\title{
Effect of clasp type and pullout location on clasp retention in different environment: In vitro study
}

\author{
Bilal Mourshed ${ }^{1}$, Fuad Abdo Al-Sabri ${ }^{2,3}$, Nashwan Ahmed Qaed ${ }^{2}$, Nader Alaizari ${ }^{4}$, \\ Hashem Motahir Al-Shamiri ${ }^{5}$, Amal Alfaqih ${ }^{6}$
}

Correspondence: Dr. Bilal Mourshed

Email: mourshedbilal@gmail.com

\begin{abstract}
'Department of Prosthetic Dentistry, Al-Farabi College, Riyadh, Saudi Arabia,

${ }^{2}$ Department of Restorative Dentistry, Al-Farabi College, Riyadh, Saudi Arabia,

${ }^{3}$ Department of Operative Dentistry, Faculty of Dentistry, Thamar University, Thamar, Yemen, ${ }^{4}$ Department of Oral Medicine and Diagnostic Sciences, Al-Farabi College, Riyadh, Saudi Arabia,

${ }^{5}$ Department of Oral and Maxillofacial Surgery,

Al-Farabi College, Riyadh, Saudi Arabia,

${ }^{6}$ Ebtisama Dental Center, Private Clinic, Sana'a, Yemen
\end{abstract}

\section{ABSTRACT}

Objective: The purpose of this study was to investigate the importance of pullout location and clasp types in two different environments to dislodge the clasp. Materials and Methods: Mandibular test models with natural premolars and molar teeth were used to test four types of clasp (each 12) (Akers, Rest plate Akers, Half and Half, and Ring clasp) with three different pullout location for each type (ring on the rest, loop on the saddle, and wax arising from both rests) in dry and natural fresh saliva environment. Each clasp was pulled out 10 times with a crosshead speed of $10 \mathrm{~mm} / \mathrm{min}$, and the force required to withdraw each was measured. Statistical Analysis Used: A one-way ANOVA and Tukey test were used. Results: The ring on the saddle pullout location has the highest retention force while ring on the rest was the lowest. In addition, ring clasp has the highest retention force. Conclusion: Clasp type and pullout location had a significant effect on the retentive force.

Key words: Akers, clasp, pullout location, removable partial denture, retention, saliva

\section{INTRODUCTION}

As the dental science is evolving to new era with visualization of digital and modern dentistry and also technique ${ }^{[1-4]}$ to analysis the status patterns of implant-supported prosthesis which becomes a predictable and safe procedure, ${ }^{[5]}$ yet the importance of removable partial denture (RPD) is not disregarded and always there is a scope to use it.

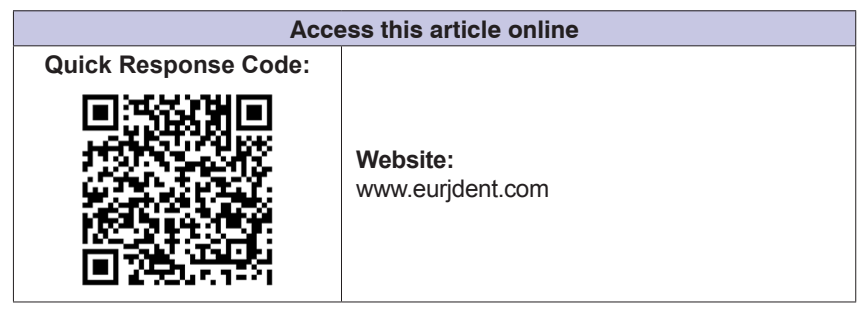

However, the developments of an RPD in dental technology allow its fabrication with satisfactory functional, esthetic outcomes, ${ }^{[6]}$ and minimum problems in the periodontal tissue. ${ }^{[7]}$

RPD generally consists of four parts as base plate, clasp, and major and minor connector of the framework. The

This is an open access article distributed under the terms of the Creative Commons Attribution-NonCommercial-ShareAlike 3.0 License, which allows others to remix, tweak, and build upon the work non-commercially, as long as the author is credited and the new creations are licensed under the identical terms.

For reprints contact: reprints@medknow.com

How to cite this article: Mourshed B, Al-Sabri FA, Qaed NA, Alaizari N, Al-Shamiri HM, Alfaqih A. Effect of clasp type and pullout location on clasp retention in different environment: In vitro study. Eur $\mathrm{J}$ Dent 2017;11:216-20.

DOI: 10.4103/ejd.ejd_70_17 
clasp was and still the most practical and popular means of retention in RPD, especially for distal extension bases. It should be designed to provide maximal retention without tipping or rotational forces to the abutment teeth. ${ }^{[8]}$

The load capacity of the clasp depends on various factors such as type, position of clasp, tooth position, clasp length, and pullout location. As a general rule, the amount of retention required to dislodge the RPD from the supporting structure should always be the minimum necessary to resist reasonable dislodging forces.

Excessive force from the clasps may cause many problems. However, regarding the retentive force provided by cobalt-chrome (Co-Cr) clasps, Ahmad et al. mentioned that the mean retentive force for a framework engaging an undercut of $0.25 \mathrm{~mm}$ with one clasp (Akers) was 4.77 N. ${ }^{[9]}$ Frank and Nicholls concluded that 3-7.5 $\mathrm{N}$ represented an acceptable amount of retention for a bilateral distal extension $\mathrm{RPD}^{[10]}$ while Sato demonstrated that $5 \mathrm{~N}$ is the required force to dislodge the clasps. ${ }^{[1]}$

Former studies used a projection on the saddle (ring, sprue) to withdrawal the clasp; $;^{[12-15]}$ other studies used loops attached to the top of each occlusal rest to pull out the frameworks by machine. ${ }^{[9,16-19]}$ However, no one investigates the importance of pullout location on the retentive force. Therefore, this study has been carried out to investigate the importance of pullout location and clasp types on retention. The null hypothesis was that the pullout location and clasp type would not affect the retention force of the clasp.

\section{MATERIALS AND METHODS}

The master casts were prepared by using a maxillary plastic model (Frasaco AG-3 WOK 40). The left maxillary second premolar tooth was removed from the plastic model and replaced by extracted first premolar tooth by duplicating with reversible hydrocolloid material then poured in dental stone. Before the dental stone was setting, two screws on each other were put $3 \mathrm{~mm}$ farther from the border of the silicon mold.

Three master casts were prepared with three premolar natural teeth and the same procedure was used to make a master cast for natural molar [Figure 1].

The casts were surveyed at zero tilt position; then, undercut depths were measured using $0.50 \mathrm{~mm}$ undercut gauge. The path of insertion was then recorded by the surveyor and tripod lines were marked for future repositioning. Rests were prepared using round diamond no. 6 (dimension $2.5 \mathrm{~mm} \times 2.5 \mathrm{~mm}$ and depth $1.5 \mathrm{~mm})^{[20]}$ and examined to ensure the size. ${ }^{[8]}$ To achieve standardization, parallel guiding plane was prepared approximately $2 \mathrm{~mm}$ on proximal surface in occlusal-gingival direction ${ }^{[8]}$ using a milling machine (AF 30, milling machine, Switzerland). The master casts were duplicated with agar and invested for waxing.

\section{Shape and location of pullout extension}

Four clasp types were selected for this study: Akers, Rest plate Akers (RPA), Half and Half $(\mathrm{H}-\mathrm{H})$, and Ring clasp. A total of $48 \mathrm{Cr}$-Co clasps were made using a standardized prefabricated wax. Each clasp type $(n=12)$ was divided into three groups $(n=4)$. Each group was designed and waxed for three different pullout locations following:

1. Ring on the rest

2. Loop on the saddle (Saddle: small projection of wax that extended from the bottom of each proximal plate)

3. Two rods waxes were arisen from both rests and joined to a ring:

o For Ring and $\mathrm{H}-\mathrm{H}$ clasp

o Because there were no two rests on the RPA clasp design, the pullout location for RPA clasp was waxed arising from the rest and the proximal plate.

o Because there were no two rests on the Akers clasp design, the pullout location for Akers clasp was arising from the thickest part of the retentive and reciprocal arm [Figure 2]. All the

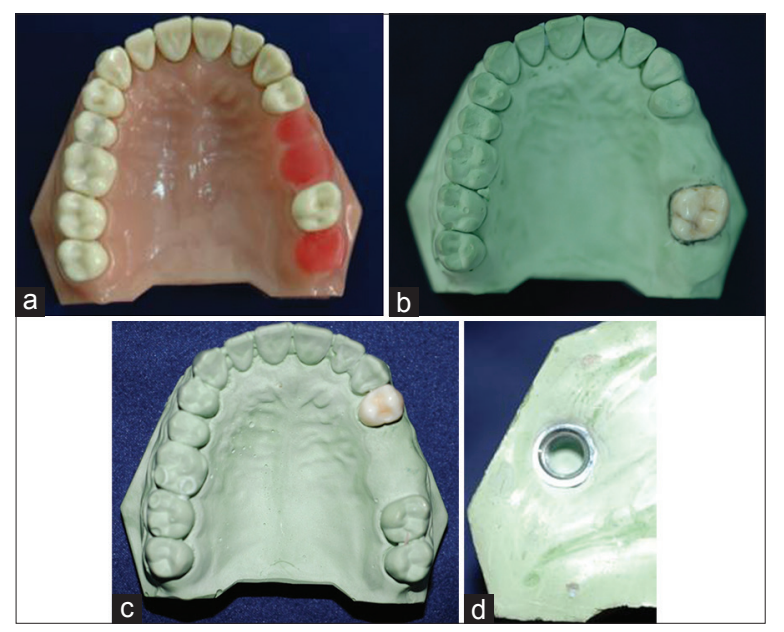

Figure 1: (a) Maxillary plastic model filled with wax, (b) prepared master casts for premolar, (c) prepared master casts for premolar-molar, (d) screws were fixed on the model 
pullout extensions were placed parallel to the path of insertion with the aid of surveyor.

Theclasps then were cast, finished, and electropolishing. Before the fitting, clasps were checked from external and internal defects using an X-ray machine (Siemens, 1448237 D3195, Germany) and then washed using a steam machine (Steam generator SG5, Italy). Care was taken to avoid touching the fitting surface that will contact the abutment. All of the laboratory and technical works were done by a single investigator.

A movable special jig was constructed to hold the master cast and fix it perpendicular to the pulling out chain. The dislodging forces were always directed vertically using a universal testing machine (Shimadzu testing machine AG-X, $10 \mathrm{~N}-10 \mathrm{KN}$, Japan) and tensile test was applied in two different environments: dry and wet (fresh natural saliva).

A tensile load was applied to each clasp 10 times for dislodging until the machine automatically stopped [Figure 3].

\section{RESULTS}

\section{The effect of pullout location}

A one-way ANOVA was conducted to compare theeffect of different pullout locations on the retention for all types of clasp. There was a significant effect of pullout location at in both environments. Ring on the rest location had the lowest retentive force compared to other locations.

Post hoc comparisons using the Tukey test indicated that significant difference in the mean retentive force

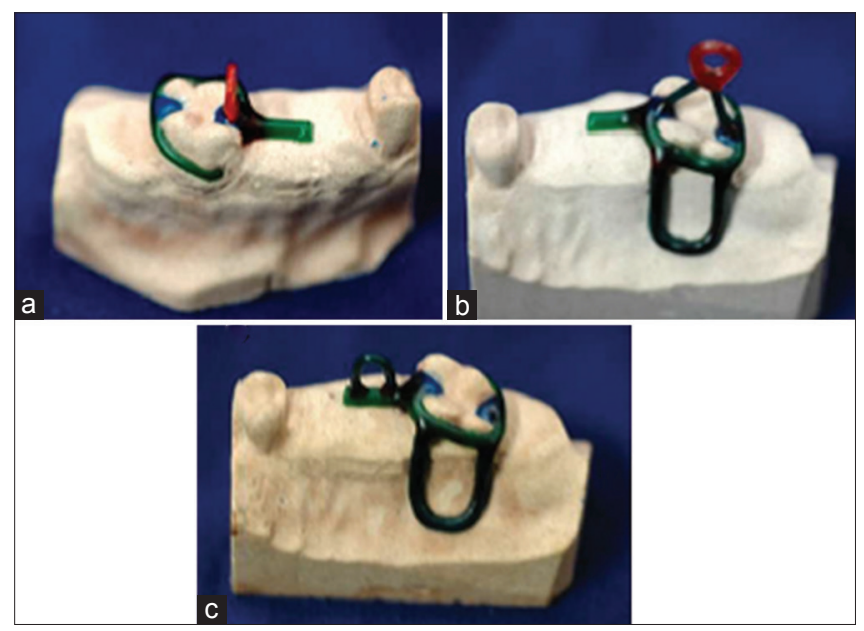

Figure 2: Preparation of different locations of pullout extension for ring clasp (a) Ring on the rest (b) loop on the saddle (c) wax arising from both rests was present between ring on the rest location and loop on the saddle location in both dry and wet environment [Tables 1 and 2].

The effect of different type of clasp on the retention A one-way ANOVA was conducted to indicate the effect of clasps design on the retentive force. There was a significant association between the forces at the four types of clasp in both environments. While ring clasp had the highest retentive force, RPA was the lowest [Tables 3 and 4].

\section{DISCUSSION}

Although digital and modern dentistry with new technique and advance treatment ${ }^{[1-5]}$ is developing faster, there is always a scope of RPD in dentistry. This

\begin{tabular}{|c|c|c|c|}
\hline Type of pullout location & $n$ & Mean & SD \\
\hline \multicolumn{4}{|l|}{ Mean dry } \\
\hline Ring on the rest & 16 & 8.96 & 5.61 \\
\hline Ring on the saddle & 16 & 13.99 & 6.33 \\
\hline Wax arising from the rest and attached to ring & 16 & 11.47 & 4.95 \\
\hline \multicolumn{4}{|l|}{ Mean NS } \\
\hline Ring on the rest & 16 & 8.50 & 5.63 \\
\hline Ring on the saddle & 16 & 13.62 & 6.75 \\
\hline Wax arising from the rest and attached to ring & 16 & 10.67 & 4.71 \\
\hline
\end{tabular}

\begin{tabular}{|c|c|c|c|c|c|}
\hline $\begin{array}{l}\text { Source of } \\
\text { variation }\end{array}$ & $\begin{array}{l}\text { Sum of } \\
\text { squares }\end{array}$ & df & $\begin{array}{l}\text { Mean } \\
\text { square }\end{array}$ & $F$ & Significant \\
\hline \multicolumn{6}{|l|}{ Mean dry } \\
\hline Between groups & 202.629 & 2 & 101.314 & 3.164 & 0.052 \\
\hline Within groups & 1440.867 & 45 & 32.019 & & \\
\hline \multicolumn{6}{|l|}{ Mean NS } \\
\hline Between groups & 211.274 & 2 & 105.637 & 3.190 & 0.051 \\
\hline Within groups & 1490.354 & 45 & 33.119 & & \\
\hline
\end{tabular}

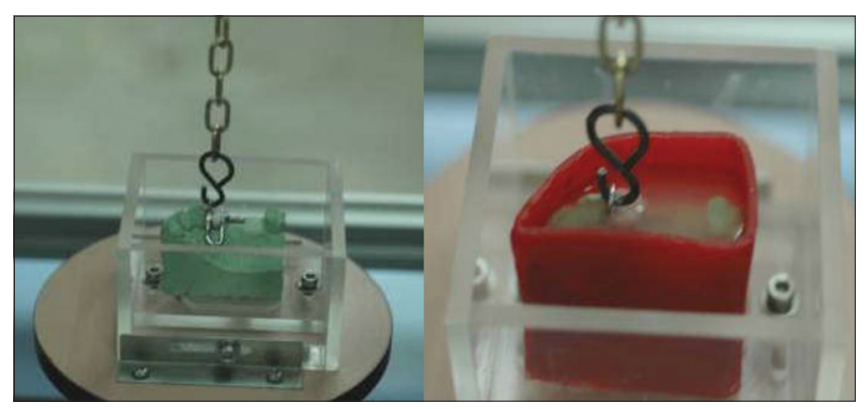

Figure 3: Testing the clasp in dry and wet environments 
study is evaluating the importance of pullout location and clasp types on retention in RPD.

The null hypothesis was rejected. The result of the study showed that the pullout location and clasp type affected the retention force of the clasp.

Metal artificial teeth have been used as a replacement for natural teeth in some studies..$^{[9,12-14,17,18]}$ However, the use of natural teeth for testing the retentive force seemed to be closer to the oral condition because the use of metal abutment tooth induces much higher friction to the surface of abutment tooth and consequence increase the retention. ${ }^{[21]}$ Because of that, in this study, natural teeth were used to assess the retentive force. ${ }^{[18,19]}$

The present study measures the retentive force of the clasp assembly separately. ${ }^{[12-15,22]}$ Various methods had been used the clasp with frameworks for measuring the retentive force. ${ }^{[9,16,17,19]}$ As a result, measuring the retention force of the entire framework including the different component of the frame would not give the absolute value of the clasp retentive force but of the entire framework. In one framework, more than one clasp was usually used, and these clasps were not identical and the load application was not transmitted equally to all clasp, so the retentive force will be determined either by the least retentive clasp in each design ${ }^{[9]}$ or assumed not only for one clasp but also for

\begin{tabular}{|c|c|c|c|}
\hline Clasp type & $n$ & Mean & SD \\
\hline \multicolumn{4}{|l|}{ Mean dry } \\
\hline Ring & 12 & 17.82 & 1.73 \\
\hline RPA & 12 & 4.86 & 1.93 \\
\hline $\mathrm{H}-\mathrm{H}$ & 12 & 8.04 & 2.36 \\
\hline Akers & 12 & 15.17 & 4.21 \\
\hline \multicolumn{4}{|l|}{ Mean NS } \\
\hline Ring & 12 & 16.89 & 1.56 \\
\hline RPA & 12 & 4.12 & 1.72 \\
\hline $\mathrm{H}-\mathrm{H}$ & 12 & 7.90 & 2.68 \\
\hline Akers & 12 & 14.82 & 5.12 \\
\hline
\end{tabular}

all clasps. ${ }^{[17]}$ Furthermore, fitting the framework will be difficult and may need extra trimming from inner surface and this may affect the result due to many limitations that occur during trimming and polishing of the framework. ${ }^{[9,17,18]}$

The location of pullout influenced the retentive force estimation of different clasp. The extension ring on the rest location had the lowest retentive force. However, loop on the saddle had the highest one. This result may be because the dislodgement of the clasp with the location of "loop on the saddle" was not directed vertically along the path of dislodgment. As observed during the withdrawal action of "loop on the saddle" location clasps, the rigid component on the clasp (minor connector or proximal plate) was bound when contacted the prepared guiding plane on the abutment therefore increase the friction between the minor connector or proximal plate and the proximal surface (guiding plane) of the abutment tooth and prevent easy dislodgment. However, at the same time, the retentive tip of the clasp did not reach the greatest contour of the tooth (survey line) and still in its greatest magnitude of resistance to remove the abutment tooth. The ring on the rest location was observed to have dislodgement directed more vertical and along the path of draw, therefore, less friction between the minor connector and proximal palate with the proximal surface of the abutment tooth. No former investigations studied the different types of pullout location to compare with. Most studies depend on one type of pullout location (some studies used projection on the saddle [ring, sprue]); ${ }^{[12-15]}$ other studies used loops attached to the top of each occlusal rest to pull out the frameworks by machine..$^{[9,16-19]}$ However, the different methods used make the comparison with our study very difficult.

On the other hand, most of the studies used Akers clasp to determine the retentive force of the clasp. ${ }^{[9,13,17]}$ However, in our study, we used different types of clasp to test the retentive force.

Regarding the retentive force provided by clasps, authors stated that the retentive force for a cast clasp

\begin{tabular}{|c|c|c|c|c|c|}
\hline Source of variation & Sum of squares & df & Mean square & $\boldsymbol{F}$ & Significant \\
\hline Mean dry between groups & 1313.314 & 3 & 437.771 & 58.338 & 0.000 \\
\hline Within groups & 330.181 & 44 & 7.504 & & \\
\hline Mean NS between groups & 1275.185 & 3 & 425.062 & 43.857 & 0.000 \\
\hline Within groups & 426.443 & 44 & 9.692 & & \\
\hline
\end{tabular}


should be at least $4-5 \mathrm{~N} \cdot{ }^{[9-11]}$ However, the retentive force in our study ranging from 4 to $17 \mathrm{~N}$ [Table 3]. These results may consider high comparing with other study. In this study, results depended on different types of clasp and the way that this clasp pulled out. In addition, the undercut used in our study $(0.50 \mathrm{~mm})$ may be another explanation for this result.

Ring clasp demonstrated the greatest retentive force (16.89). This is maybe due to its long arm that nearly encircles all of a tooth. ${ }^{[20]}$ The longer clasps required a greater load to dislodge them from the tooth. This requirement is probably due to a large frictional interface between the clasp and tooth surface. ${ }^{[14]}$

The test was performed in two environments: dry and wet. Natural fresh saliva was used as the wet condition. It is used because it has been recommended that viscosity should be determined from fresh saliva samples. ${ }^{[23]}$

Most of former studies measured the retentive force in dry condition. ${ }^{[9,10,12-17,22]}$ However, some of former studies used either natural saliva ${ }^{[21,24]}$ or saliva substitute ${ }^{[18,19]}$ to obtain the wet condition. However, denture retention should be examined under wet condition, especially for human enamel and porcelain to be clinically relevant. ${ }^{[21]}$

\section{CONCLUSION}

The pullout location had a significant effect on the retentive force. While a loop on the saddle had the greatest retentive force, ring on the rest had the lowest one. Clasp type influenced the increase of the retentive force of the clasp.

\section{Financial support and sponsorship Nil.}

\section{Conflicts of interest}

There are no conflicts of interest.

\section{REFERENCES}

1. Cicciù M, Cervino G, Bramanti E, Lauritano F, Lo Gudice G, Scappaticci L, et al. FEM analysis of mandibular prosthetic overdenture supported by dental implants: Evaluation of different retention methods. Comput Math Methods Med 2015;2015:943839.

2. Cicciu M, Bramanti E, Matacena G, Guglielmino E, Risitano G. FEM evaluation of cemented-retained versus screw-retained dental implant single-tooth crown prosthesis. Int J Clin Exp Med 2014;7:817-25.

3. Cicciù M, Risitano G, Maiorana C, Franceschini G. Parametric analysis of the strength in the "Toronto" osseous-prosthesis system. Minerva Stomatol 2009;58:9-23.

4. Lauritano F, Runci M, Cervino G, Fiorillo L, Bramanti E, Cicciù M. Three-dimensional evaluation of different prosthesis retention systems using finite element analysis and the Von Mises stress test. Minerva Stomatol 2016;65:353-67.

5. Cicciù M, Bramanti E, Cecchetti F, Scappaticci L, Guglielmino E, Risitano G. FEM and Von Mises analyses of different dental implant shapes for masticatory loading distribution. Oral Implantol (Rome) 2014;7:1-10.

6. Dula LJ, Shala KS, Pustina-Krasniqi T, Bicaj T, Ahmedi EF. The influence of removable partial dentures on the periodontal health of abutment and non-abutment teeth. Eur J Dent 2015;9:382-6.

7. Bilgin MS, Baytaroglu EN, Erdem A, Dilber E. A review of computer-aided design/computer-aided manufacture techniques for removable denture fabrication. Eur J Dent 2016;10:286-91.

8. Phoenix RD, Cagna DR, DeFreest CF. Stewart's Clinical Removable Partial Prosthodontics. $4^{\text {th }}$ ed. Chicago: Quintessence Publishing Co., Inc.; 2008.

9. Ahmad I, Sherriff M, Waters NE. The effect of reducing the number of clasps on removable partial denture retention. J Prosthet Dent 1992;68:928-33.

10. Frank RP, Nicholls JI. A study of the flexibility of wrought wire clasps. J Prosthet Dent 1981;45:259-67.

11. Sato Y. Clinical methods for adjusting retention force of cast clasps. J Prosthet Dent 1999;82:557-61.

12. Arda T, Arikan A. An in vitro comparison of retentive force and deformation of acetal resin and cobalt-chromium clasps. J Prosthet Dent 2005;94:267-74.

13. Kim D, Park C, Yi Y, Cho L. Comparison of cast Ti-Ni alloy clasp retention with conventional removable partial denture clasps. J Prosthet Dent 2004;91:374-82.

14. Marei MK. Measurement (in vitro) of the amount of force required to dislodge specific clasps from different depths of undercut. J Prosthet Dent 1995;74:258-63.

15. Rodrigues RC, Ribeiro RF, de Mattos Mda G, Bezzon OL. Comparative study of circumferential clasp retention force for titanium and cobalt-chromium removable partial dentures. J Prosthet Dent 2002;88:290-6.

16. Firtell DN. Effect of clasp design upon retention of removable partial dentures. J Prosthet Dent 1968;20:43-52.

17. Ahmad I, Waters NE. Value of guide planes in partial denture retention. J Dent 1992;20:59-64.

18. LaVere AM. Clasp retention: The effects of five variables. J Prosthodont 1993;2:126-31.

19. Soo S, Leung T. Hidden clasps versus $C$ clasps and I bars: A comparison of retention. J Prosthet Dent 1996;75:622-5.

20. Carr AB, Brown DT. McCracken's Removable Partial Prosthodontics. $12^{\text {th }}$ ed. St. Louis: Elsevier Mosby; 2011.

21. Sato Y, Abe Y, Yuasa Y, Akagawa Y. Effect of friction coefficient on Akers clasp retention. J Prosthet Dent 1997;78:22-7.

22. Bridgeman JT, Marker VA, Hummel SK, Benson BW, Pace LL. Comparison of titanium and cobalt-chromium removable partial denture clasps. J Prosthet Dent 1997;78:187-93.

23. Rantonen PJ, Meurman JH. Viscosity of whole saliva. Acta Odontol Scand 1998;56:210-4.

24. Kusy RP, Whitley JQ. Influence of fluid media on the frictional coefficients in orthodontic sliding. Semin Orthod 2003;9:281-9. 